\title{
Formação interdisciplinar no jornalismo: uma experiência de articulação entre as disciplinas de Linguagem de Programação Visual e Oratória
}

\author{
Interdisciplinary training in journalism: \\ an experience of articulation between the disciplines of Visual \\ Programming Language and Oratory
}

Thaisa Cristina Bueno ${ }^{1}$

Lucas Santiago Arraes Reino ${ }^{2}$

Mariana Guedes Falcao ${ }^{3}$

Resumo: Este artigo é resultado de uma pesquisa aplicada que interligou as disciplinas de Oratória e Linguagem de Programação Visual no curso de Jornalismo na UFMA de Imperatriz. A proposta foi testar uma didática interdisciplinar e prática com o intuito de promover uma reflexão inicial sobre a formação na área e a viabilidade em incluir nesse processo estudos sobre linguagem de programação por meio da criação de aplicativos. A proposta de levar alunos, sem experiência anterior com a linguagem de

\footnotetext{
${ }^{1}$ Doutora em Comunicação pela Pontificia Universidade Federal do Rio Grande do Sul (2015), Mestre em Letras pela Universidade Federal do Mato Grosso do Sul (2007), professora adjunta no curso de Comunicação Social - Jornalismo na Universidade Federal do Maranhão. Atualmente é coordenadora do programa de Mestrado em Comunicação/Capes, na UFMA em Imperatriz.
}

${ }^{2}$ Mestre em Ciência da Informação pela UNB (2005), doutor em Comunicação pela Pontifícia Universidade Federal do Rio Grande do Sul (2016), professor adjunto no curso de Comunicação Social - Jornalismo na Universidade Federal do Maranhão.

${ }^{3}$ Mestre em Comunicação e Cultura Contemporâneas pela Universidade Federal da Bahia (2014) e graduada em Comunicação Social com habilitação em Jornalismo pela Universidade Estadual do Piauí (2011). É autora do livro "Temas em jornalismo digital: histórico e perspectivas", publicado em 2018 pela Editora Intersaberes. Academicamente realiza pesquisas voltadas aos estudos das Teorias do Jornalismo, Mídias Digitais e Jornalismo Digital.

Interfaces da Educ., Paranaíba, v.11, n.32, p. 515 - 541, 2020 
softwares, a produzir conteúdo e o próprio APP teve o objetivo de levantar a discussão sobre o quanto uma formação mais convergente, incluindo domínio técnico de algumas linguagens, como softwares, e interdisciplinar, pode contribuir para o desenvolvimento de um jornalista mais preparado o mercado e mais autônomo para atuar na condução da sua própria carreira.

PALAVRAS-CHAVE: Aplicativos. Formação. Jornalismo. Pesquisa Aplicada. Imperatriz.

Abstract: This article is the result of an applied research that interconnected the subjects of two classes - Oratory and Laboratory of Graphic Design - in the course of Journalism of the Federal University of Maranhão, in the city of Imperatriz. The aim was to test an interdisciplinary and practical didactics that intends to promote a reflection about the formation in the area of Communication and the feasibility of adopting programming languages as curriculum through the creation of applications. This effort meant to encourage students unexperienced with programming languages to produce content and publish the application itself. Our main goal was to discuss how convergent, technical training, is essential to the development of a journalist more prepared and autonomous, that is able to steer his or her career in a better way.

Key Words: Applications. Formation. Journalism. Applied research. Imperatriz.

\section{Introdução}

O jornalismo é impactado constantemente pelo surgimento de novas tecnologias de comunicação. O ritmo acelerado com que surgem inovações impulsiona um exercício constante de atualização não só por parte dos profissionais, mas dos próprios cursos de Comunicação, onde particularmente se busca promover uma formação em diálogo com a Interfaces da Educ., Paranaiba, v.11, n.32, p. 315-341, 2020 
realidade do mercado e da sociedade, cada vez mais conectada e midiatizada. Lopes e Silva (2016, p.137) reconhecem essa realidade ao enfatizarem que nos últimos 20 anos "tem-se verificado uma grande transformação no campo profissional do jornalismo, em seu saber-fazer e, como consequência, no ensino de jornalismo no Brasil".

Acerca dessas mudanças ocorridas a partir da inserção de novas tecnologias no "fazer jornalismo", Santos (2014) pondera que seu impacto inclui a reconfiguração da própria identidade profissional. Particularmente no que tange à formação desse novo jornalista, a pesquisadora Schwingel (2015) pondera que o novo perfil indica um profissional mais habilidoso na técnica.

\begin{abstract}
Precisa ter noções, claro, das tecnologias da internet. Tem que ter noções de programação, noções de design de interfaces, tem, sim, que ter noções de toda tecnologia de programação, de base dados, da linguagem de programação, do www e dos aplicativos, das APIs, das interfaces e de como fazer isso. Idealmente, sim, saber o mínimo de programação, principalmente, nessa questão da programação voltada a banco de dados (SCHWINGEL, 2015, p. 3).
\end{abstract}

Embora o posicionamento não seja uma unanimidade - nomes como Marcondes Filho (2000), Moretzsohn (2002), Marshall (2016), entre outros, acreditam que, em um cenário influenciado fortemente pela tecnologia, o jornalista deveria ter uma formação mais atenta à base humanística -, o fato é que as modificações nas rotinas dos veículos acabam por incentivar, ou ao menos instigar a reflexão sobre, a necessidade de mudança de postura também das universidades. Inclusive, o mercado profissional de jornalismo vez ou outra recorre à academia para encontrar soluções para questões enfrentadas no dia a dia. Apesar de poucas iniciativas deste tipo no Brasil, como o Ubilab (Laboratório de Pesquisa em Mobilidade e Convergência Midiática) da PUC - RS, que realiza pesquisas aplicadas em Comunicação e Jornalismo, essa prática permite um trabalho com resultados acadêmicos e práticos, beneficiando ambos os envolvidos. Exemplo recente é a criação pelo Unilab do G1 Eleições, solução para eleições no portal de notícias G1 a partir do uso de assistentes pessoais online ativados por voz para consumo 
de informações jornalísticas. A parceria entre pesquisadores e estudantes e a Globo resultou em uma proposta inédita em um portal de notícias no Brasil ${ }^{1}$.

No topo dos vetores tecnológicos de mudança estão os smartphones, aparelhos celulares com capacidade de realização de processos complexos, como instalação dos mais variados programas, os chamados APPs, que permitem, para além da tradicional ligação, produzir e editar fotografias e vídeos, gravar e editar áudios, acessar a internet em diferentes plataformas e mais uma infinidade de ações que impactam a rotina de trabalho na mídia. Atualmente, somando os APPs disponiveis nas duas principais lojas de download, Google Play para Android e APP Store para iOS, são mais de 5 milhões de opções disponiveis. Certamente muitos repetidos, mas há 10 anos, em 2008, eram apenas $800^{2}$.

Calado e Junior (2015) apontam como consequência da popularização dos smartphones o aumento da ubiquidade de informações, ou seja, o acesso a uma infinidade de dados em quase todos os lugares. Com os APPs, as possibilidades de uso desses dados também se amplificam: "para o jornalista, isso significa não apenas uma maior disseminação de conteúdo, mas a possibilidade de noticiar em tempo real; editar e enviar informações para a redação no momento da cobertura, além da possibilidade de entrar em contato com as fontes" (CALADO; JUNIOR, 2015, p.42).

É por essa conjuntura que se permite pensar em o quanto os novos jornalistas precisam estar preparados e os cursos adotarem um modelo que permita encontrar uma formação mais completa. Com essa situação em mente, os professores do curso de Comunicação Social - Jornalismo, da Universidade Federal do Maranhão, responsáveis pelas disciplinas de Oratória e Linguagem de Programação Visual, realizaram no primeiro semestre de 2018 um trabalho em conjunto entre os acadêmicos das duas disciplinas a fim de desenvolver as habilidades dos estudantes para publicar

\footnotetext{
1 Ver mais em: http://www.pucrs.br/blog/laboratorio-da-pucrs-cria-solucao-inedita-paraas-eleicoes-no-portal-de-noticias-g1/. Acesso em: 23 fev. 2019.

2 Disponivel em: http://www.infotecblog.com.br/2017/07/03/existem-mais-de-5-milhoesde-aplicativos-no-mundo/. Acesso em: 12 fev. 2019.
}

Interfaces da Educ., Paranaíba, v.11, n.32, p. 515 - 541, 2020 
conteúdos em ambientes digitais para dispositivos móveis, produzindo conteúdo sobre Oratória em aplicativos feitos para celular. De caráter essencialmente prático, a disciplina de Oratória contempla aspectos teóricos relevantes para o curso, como estruturação de discursos, técnicas de argumentação e uso adequado da linguagem. A proposta de sistematizar conceitos em um aplicativo, além de atender a diferentes objetivos da disciplina de Linguagem de Programação Visual, aproxima os alunos da teoria referente à argumentação e oratória (usada como requisito para a produção do conteúdo) e desperta nos alunos interesse por uma estruturação do conteúdo, adequação ao público e busca por outras fontes.

$O$ resultado desta experiência está detalhado neste artigo, em formato de pesquisa aplicada, experimental e descritiva. Trata-se de um experimento, por meio de atividade prática, com 26 alunos do curso de Jornalismo da UFMA matriculados em duas disciplinas do terceiro semestre regular que foram orientados a produzir, em grupos, um aplicativo para celular com conteúdo debatido na disciplina de Oratória tendo como base o livro "A Arte de Argumentar" (ABREU, 2013).

A proposta de levar alunos, sem experiência anterior com a linguagem de softwares, a produzir conteúdo e o próprio APP, teve o objetivo de levantar a discussão sobre o quanto uma formação mais convergente, incluindo domínio técnico de algumas linguagens, como softwares, e interdisciplinar, pode contribuir para o desenvolvimento de um jornalista mais preparado o mercado e mais autônomo para atuar na condução da sua própria carreira, inclusive no sentido de propor novos negócios. O estudo esteve centrado em entender se a proposta de uma atividade mais prática e integrada, incluindo uma linguagem de software, em geral mais próxima de cursos tecnológicos e das ciências exatas, poderia ser viável e traria bons resultados de aprendizagem no curso de Jornalismo.

O objetivo deste artigo, neste sentido, é apresentar algumas reflexões sobre o experimento e com isso contribuir para a discussão sobre a formação mais adequada ao campo do Jornalismo. Em particular, o texto se propõe a levantar algumas bases sobre as facilidades e dificuldades de se pensar uma Interfaces da Educ., Paranaíba, v.11, n.32, p. 515 - 541, 2020 
didática que integre e amplie as habilidades do jornalismo para além das tradicionais produções, escrita e divulgação. $\mathrm{O}$ argumento do texto foi divido em dois momentos: inicialmente apresenta-se uma compilação de textos sobre os desafios da formação em Jornalismo em face às transformações geradas pela popularização das Tecnologias Digitais de Informação e Comunicação (TICs); e em seguida há uma explanação sobre a metodologia adotada no experimento e a descrição de todo o processo, seus acertos, erros e resultados.

\section{Jornalismo e novas tecnologias: aspectos da formação em jornalismo}

As tecnologias digitais de Informação e Comunicação têm provocado alterações nas experiências e representações da realidade social, bem como originado novas formas de socialização e uma lógica diferenciada de produção e recepção de informações, inclusive jornalísticas (CASTELLS, 2003, 2007; LEMOS, 2004; SAAD, 2003). O que Saad (2015, p.1) nomeia de "contemporaneidade digital" designa uma série mudanças nas práticas de sociabilidade, formas de percepção da mente humana e condições econômicas, políticas, institucionais e culturais.

No jornalismo, e na Comunicação de forma mais ampla, a partir da década de 1980, as inovações são consequências do desenvolvimento tecnológico, especialmente das chamadas mídias digitais. A própria concepção de inovação no jornalismo, segundo Franciscato (2010), "não pode ser considerada como um investimento isolado em modernização industrial, mas caracterizada também como um aporte que modifica as rotinas e processos de trabalho do jornalista, bem como o perfil e qualidade do produto jornalístico". Ocorre, portanto, em níveis de produtos e processos.

Barbosa (2013) caracteriza o cenário atual como marcado pela horizontalidade nos fluxos de produção, edição e distribuição, circulação e recirculação dos conteúdos, o que resulta num continuum multimídia de cariz dinâmico. A autora identifica uma quinta geração de desenvolvimento para o jornalismo nas redes digitais, que tem as mídias móveis como propulsoras de um novo ciclo de inovação. De acordo com Scolari (2016, p. Interfaces da Educ., Paranaiba, v.11, n.32, p. 515 - 541, 2020 
183), "um novo meio de comunicação entrou no ecossistema de mídia, um meio com os seus próprios modelos de negócios, gramática, práticas de produção e dinâmicas de consumo". A comunicação móvel, nesse sentido, representa uma nova instância de reconfigurações para as práticas processuais e conteúdos jornalísticos. "As mídias móveis, especialmente os smartphones e tablets, são os novos agentes que reconfiguram a produção, publicação, a distribuição, a circulação, a recirculação, o consumo e a recepção de conteúdo jornalístico em multiplataforma", (BARBOSA, 2013, p.42).

O avanço das ferramentas e tecnologias de acesso à web e a popularização do uso dos dispositivos móveis, especialmente tablets e smartphones para acesso a notícias revela a mobilidade como divisora de águas nos campos da Comunicação e do Jornalismo. Um exemplo é o uso de mídias sociais para conteúdo jornalístico, parte de um processo orientado não apenas pela tecnologia, mas pelas relações sociais e culturais que se constroem em seu entorno, seja entre emissores e receptores, mídias sociais e organizações jornalísticas. Dados dos Reuters Institute Digital News Report 2016 apontam o crescente uso de mídias sociais e agregadores, entre os anos de 2015 e $2016^{3}$, como principais fontes de notícias em diferentes países e no aumento contínuo do acesso a notícias através de dispositivos móveis, especialmente smartphones ${ }^{4}$. Além disso, os formatos noticiosos têm se reconfigurado diante do desafio do jornalismo de cativar os leitores principalmente através de estratégias de convergência nas áreas tecnológica, empresarial, profissional e, sobretudo, editorial. Exemplo são as narrativas multimídia e transmídia, desenvolvidas não apenas para a web e na web, mas também para e em dispositivos móveis, ou seja, em múltiplas plataformas. Elas exigem habilidades profissionais do jornalista, que precisa

\footnotetext{
3 Em janeiro de 2015, o Snapchat lançou o Discover. No mesmo ano o Google lançou o Digital News Initiative em abril, o Google News Lab em junho e o Google Accelerated Mobile Pages em outubro. Paralelamente a isso, o Facebook lançou o Instant Articles, a Apple lançou o agregador de notícias Apple News e o Twitter lançou o Moments, em maio, setembro e outubro respectivamente. Atualmente, estas aplicações continuam se desenvolvendo, transformando mídias sociais em "editores" e "publicadores" de conteúdo.

${ }^{4}$ Dados dos Reuters Institute Digital News Report 2016. Disponivel em: http://bit.ly/2dMOlag. Acesso em: 15 ago. 2016.

Interfaces da Educ., Paranaíba, v.11, n.32, p. 515 - 541, 2020
} 
lidar com design de interface e planejamento de interação com os usuários (ALBORNOZ, 2006).

A formação em Jornalismo, portanto, deve agregar conteúdos que contemplem esse cenário e insiram o aluno no contexto contemporâneo digital. É o que Becker (2016) chama de "formação convergente", que na sua avaliação concebe a passagem do desenvolvimento de um jornalista "monomídia" para outro "polivalente". A mudança no paradigma, para a autora, apesar das criticas que recebeu por professores e profissionais a partir da integração das grandes redações, principalmente por conta da precarização e acúmulo de funções, nem sempre remuneradas, é uma mudança imprescindível, já que se trata de uma reconfiguração na própria sociedade.

Esta opinião é ratificada por Machado (2010) ao defender a necessidade de se reformular os projetos de curso, incluindo um modelo de ensino que dê "[...] lugar a metodologias de ensino baseadas no aprendizado simultâneo e gradativo das diversas linguagens e na produção orientada em equipe adaptada a múltiplas plataformas" (MACHADO, 2010, p. 20).

\section{Curso de jornalismo da UFMA e as disciplinas-teste nesta pesquisa}

O curso de Jornalismo na UFMA de Imperatriz começou a funcionar em 2006 e até 2018 tinha formado aproximadamente 230 novos jornalistas. A cidade, localizada a quase 600 quilômetros da capital, São Luís, conta atualmente com sete emissoras de TV, oito de rádio, dois jornais impressos em circulação, um site de cunho comercial e cerca de 60 blogs atuantes. A graduação em Jornalismo no local é a única no interior do Maranhão ofertada por instituição pública e também a única da cidade.

Embora a grade do curso adote disciplinas autônomas, o programa prevê parcerias interdisciplinares na produção de conteúdo e na construção de produtos. Um exemplo disso é o site Imperatriz Notícias (www.imperatriznoticias.ufma.br), que integra pelo menos quatro disciplinas diferentes e de distintos semestres. 
$\mathrm{Na}$ pesquisa aqui apresentada, das duas disciplinas envolvidas Laboratório de Programação Visual e Oratória - a primeira é que mais se aproxima da proposta de inclusão das ferramentas digitais e encabeça a ideia de formação convergente. Ainda assim, a inclusão da segunda disciplina, de base teórica e práticas bastante distintas, destacam o caráter interdisciplinar do estudo, que dialoga com perfeição com o debate sobre formação convergente. Afinal, como ponderava Japiassu (1976, p. 74), a interdisciplinaridade pode ser caracterizada "[...] como um nível em que a colaboração entre as diversas disciplinas que conduz a interações propriamente ditas, isto é, há certa reciprocidade nos intercâmbios, de tal forma que, no final do processo interativo, cada disciplina saia enriquecida". Deste modo, e a fim de descrever melhor o universo da pesquisa, vale detalhar melhor as duas disciplinas envolvidas no experimento.

A disciplina de Laboratório de Programação Visual é oferecida regularmente para os acadêmicos do terceiro semestre do curso e tem como foco debater e aplicar estudos sobre a questão visual das produções jornalísticas, bem como discutir a respeito de usabilidade: como dispor os conteúdos e quais formas usar para alcançar melhores resultados comunicacionais. Os smartphones, como dispositivos que fazem parte do espaço ocupado por veículos para divulgação de conteúdo, estão presentes entre os temas previstos nas aulas.

Já a ementa da disciplina de Oratória traz itens como "Argumentação e organização da atividade intelectual" e "Construção argumentativa e figuras de retórica" (Referência do PPC do curso), cujo estudo se deu a partir do livro "A Arte de Argumentar" (ABREU, 2013). O objetivo, nestes aspectos, é apresentar aos alunos diferentes técnicas argumentativas e figuras de retórica, alinhadas ao entendimento de gerenciamento de informação e relação para a construção de um bom discurso. Tais aspectos teóricos devem ser entendidos como ferramentas, cuja adequação é imprescindível para o bom uso no discurso, e não como artefatos a serem decorados ou subutilizados. 
A convergência entre as disciplinas se dá ao passo que o arsenal teórico requisitado sobre "argumentação" na disciplina de Oratória adequase à proposta de estruturação de conteúdo em um aplicativo para celular, contribuindo para que os alunos fixem o conteúdo ao buscar estrutura-lo em um produto específico e para um público específico que ultrapassa, inclusive, o âmbito dos estudantes de Jornalismo.

\section{Metodologia adotada e perfil do sujeito de pesquisa}

Com a finalidade de refletir sobre uma possivel didática mais convergente na formação do jornalista, esta pesquisa optou por uma base metodológica aplicada, experimental e descritiva, que permite "testar" uma hipótese para posteriormente pensar uma proposição. Marconi e Lakatos (2002, p. 20) definem pesquisa aplicada por seu foco de interesse na prática: "[...] que os resultados sejam aplicados ou utilizados, imediatamente, na solução de problemas que ocorrem na realidade". Sobre o assunto, Santaella (2001) destacou que se trata de levantamentos cuja "motivação principal [...] está na contribuição para resolver um problema". Além disso, outra característica que marca a pesquisa aplicada é o seu caráter experimental, em geral em laboratórios ou espaços de controle de variáveis (FRANCISCATO, 2010).

No levantamento aqui apresentado há uma experimentação no sentido de que se buscou propor uma atividade de criação (produção de aplicativo e conteúdo) para um grupo de alunos sem experiência anterior com a linguagem de softwares, a fim de averiguar o quanto a adoção deste tipo de atividade poderia ser viável na rotina de aula de um curso de Jornalismo, e, quem sabe, propor no futuro, a partir da verificação de resultados, acertos e dificuldades, a implementação de projetos integrados e uma formação mais convergente.

Participaram do experimento, realizado entre maio e junho de 2018, 26 discentes matriculados nas duas disciplinas. Como o curso é vespertino, a maioria dos estudantes é jovem. Neste estudo, especificamente, a turma era formada por acadêmicos entre 18 e 23 anos ( 25 deles) e, apenas, um com 31 Interfaces da Educ., Paranaíba, v.11, n.32, p. 515 - 541, 2020 
anos, ou seja, um grupo de pessoas que já nasceu na era digital e que, de maneira geral, está familiarizado com o uso do celular, haja vista que os smartphones chegaram ao Brasil em 2000, época em que esses jovens estavam nascendo, e de lá para cá o aparelho só se popularizou, bem como seus recursos. Entre os sujeitos da pesquisa, 15 são meninas e 11 são meninos, o que afiança à amostra um caráter equilibrado quanto ao gênero dos participantes.

Ainda com o intuito de entender melhor o perfil desses sujeitos, a fim de identificar também seu desempenho na atividade/pesquisa, foi perguntado a eles sobre qual o sistema operacional usavam no celular, bem como sua experiência anterior a esta ação com linguagem de programação e desenvolvimento de aplicativos e software. Sobre o sistema operacional mais utilizado, a maioria (21 deles) afirmou usar o Android, seguida do IOS. Nenhum deles usa o WindowsOS. A preferência pelo sistema do Google ratifica números internacionais que mostram que o sistema é o mais utilizado desde 2017, conforme relatório da StatCounter daquele ano.

A maioria não tinha nenhum conhecimento sobre linguagem de programação (18 disseram isso) e 7 consideram seu conhecimento "básico", ou seja, 25 deles não podem ser considerados experientes no assunto. Entre os que assumiram que conheciam bem este tipo de linguagem houve apenas um, e ninguém assumir ter conhecimento avançado na área investigada. Sobre o desenvolvimento de aplicativos, ninguém disse ter tido essa experiência antes da atividade proposta nesta pesquisa; todos assumiram que usam aplicativos já prontos, mas não tinham tido oportunidade de propor um novo. Com relação à experiência com software, apenas quatro participantes disseram que tinham conhecimento básico, os demais não assumiram ter tido nenhuma experiência.

Durante a atividade, foram criados pelos acadêmicos 10 aplicativos. Os próprios discentes definiram seus grupos de trabalho e receberam o prazo de 30 dias para desenvolver o conteúdo e a forma de organização do produto. Para trabalhar de forma laboratorial a criação de aplicativos, além de usar o InDesign, programa de editoração gráfica da Adobe, para gerar telas simulando um aplicativo e a disposição dos conteúdos, foi escolhido o site Interfaces da Educ., Paranaíba, v.11, n.32, p. 515 - 541, 2020 
Fábrica de Aplicativos (www.fabricadeaplicativos.com.br), uma plataforma gratuita de criação de APPS para celular que permite uma grande gama de ações, como listar conteúdo de sites de notícia, de vídeos do Youtube, fórum de debates, entre outros. Uma característica que encorajou a adoção deste foi o fato de que todo o trabalho produzido pelo sistema visual do APP não exige conhecimento de programação.

\begin{abstract}
A Fábrica de Aplicativos é uma plataforma "faça você mesmo" gratuita para construção de aplicativos e fácil de usar. Nós ajudamos nossos usuários, os appers, a criar apps fantásticos e profissionais, que podem ser editados e publicados com a maior facilidade. Não é necessário saber programação e nem ter conhecimento técnico para desenvolver seu aplicativo para todos os smartphones (FÁBRICA DE APLICATIVOS, 2018, s/p [online]).
\end{abstract}

De caráter essencialmente prático, optou-se por alinhar os interesses teóricos da disciplina de Oratória à de Programação Visual com o intuito de promover, tanto o estudo das temáticas destacadas na primeira matéria, quanto o exercício em laboratório para produção de um aplicativo para dispositivos móveis. Os alunos, portanto, tiveram liberdade para estruturar o conteúdo na plataforma digital (aplicativo), inclusive fazendo uso de conteúdo multimídia e hipertextual (matérias, vídeos, quizes etc.). Essencialmente, o conteúdo do aplicativo deveria trazer pontos sobre "as condições da argumentação", "as técnicas argumentativas", "os lugares da argumentação" e "figuras retóricas", destacados no livro (ABREU, 2013).

Na programação visual do $A P P$ foi iniciado o projeto conhecendo cada uma das opções oferecidas pela Fábrica. Como o sistema gratuito, é possível publicar até 10 abas com uma ferramenta cada, como textos, galeria de fotos, listagem de vídeos ou de músicas de outros sites, sistema de contato, integração com o Facebook, mapas, página da Internet, mural, leitor e RSS e agenda. Cada uma das ferramentas foi abordada em conjunto pelos acadêmicos, guiados pelo professor da disciplina, para analisar as possibilidades de uso dos recursos. 
O passo seguinte foi definir que conteúdos e que formas eles teriam no aplicativo, se seriam usados texto, vídeo, foto ou outra possibilidade disponivel. O planejamento do conteúdo foi feito a partir das conversas entre os alunos e de testes feitos com o aplicativo. Ao invés de projetar todo o aplicativo e depois colocá-lo no sistema do Fábrica, foi decidido fazer diretamente os testes na plataforma, para desenvolver o conhecimento dos acadêmicos, mas também para entender as limitações que eles teriam.

Por duas semanas os acadêmicos trabalharam com os conteúdos e as possibilidades de publicação, tanto em suas casas, com atividades dirigidas, quanto no laboratório de multimídia da universidade, sob orientação dos professores. Além de entregar o produto final, os estudantes responderam um questionário sobre o trabalho realizado, uma autoavaliação, e foram orientados a enviar para mais de 200 pessoas os links do aplicativo, criado com uma enquete para pessoas de seu círculo de conhecidos e agregando ao aprendizado noções de divulgação, caras para qualquer produto de mídia.

Deste modo a análise dos resultados parte dessas três etapas:

- Etapa 1 - Produto final: foram selecionados os cinco trabalhos mais significativos produzidos para a pesquisa. A análise do produto permite enxergar as habilidades técnicas e domínio da ferramenta, dois pilares para uma formação que tenha como foco o domínio dessas ferramentas.

- Etapa 2 - Autoavaliação: os alunos foram instigados a responder um questionário com cinco perguntas semiestruturadas com o objetivo de entender, a partir do experimento, como vivenciaram a experiência, suas dificuldades e se conseguem fazer uma relação com este conhecimento e o mercado profissional.

- Etapa 3 - Avaliação externa: a última etapa inclui uma enquete com 200 pessoas, que receberam o aplicativo para avaliarem. Outro questionário foi produzido com esse intuito. Embora a enquete não tenha caráter de pesquisa, o retorno do público para o trabalho permite refletir sobre estratégias de divulgação. 
Os nomes dos acadêmicos foram preservados.

\section{Etapa 1: Produto final}

Ao todo dez aplicativos foram desenvolvidos durante o experimento. Todos adotaram recursos textuais e fotográficos, alguns usaram recursos de vídeo como acesso a uma lista de vídeos do Youtube, ou de interação, como fóruns e formulário de contato. Houve casos de uso de recursos como um jogo de perguntas e respostas e venda de livros sobre oratória no próprio aplicativo.

Entre as recomendações para a produção dos aplicativos, os professores pediram que fossem planejados para pessoas da idade dos próprios alunos, faixa etária entre 18 e 23 anos, e que não tivesse foco apenas nas disciplinas, mas pensado como se pudesse ser ofertado como produto no mercado local. A proposta de uso do livro sobre argumentação para desenvolvimento de conteúdo sobre oratória é que este deveria servir como base para que os alunos compilassem pressupostos teóricos e dicas para a prática de falar em público, levando em consideração que se trata de um tema de interesse geral. Essas duas premissas fizeram com que alguns grupos pensassem, inclusive, em formas de rentabilizar com os APPs, oferecendo serviços gratuitos iniciais e cobrando por alguns mais aprofundados no futuro.

Ficou a cargo de cada grupo a definição de todos os recursos visuais e identidade para os aplicativos. A recomendação para os nomes e para o endereço temporário dos aplicativos foi o de serem simples de escrever, curtos e com o mínimo de confusão possível. Para análise e descrição do presente estudo foram selecionadas cinco produções, que copilam os resultados mais comuns entre os trabalhos apresentados.

Aplicativo Speech- (https://app.vc/speech1) - Neste trabalho os acadêmicos optaram por um visual limpo, com azul e branco. Usaram textos, dicas, vídeos, um espaço para que os usuários escrevessem discursos, glossário de conceitos, biografias de oradores famosos e lista de 
publicações feitas no Twitter, perfil criado unicamente para dar suporte ao $A P P$.

Figura 1. Aplicativo Speech

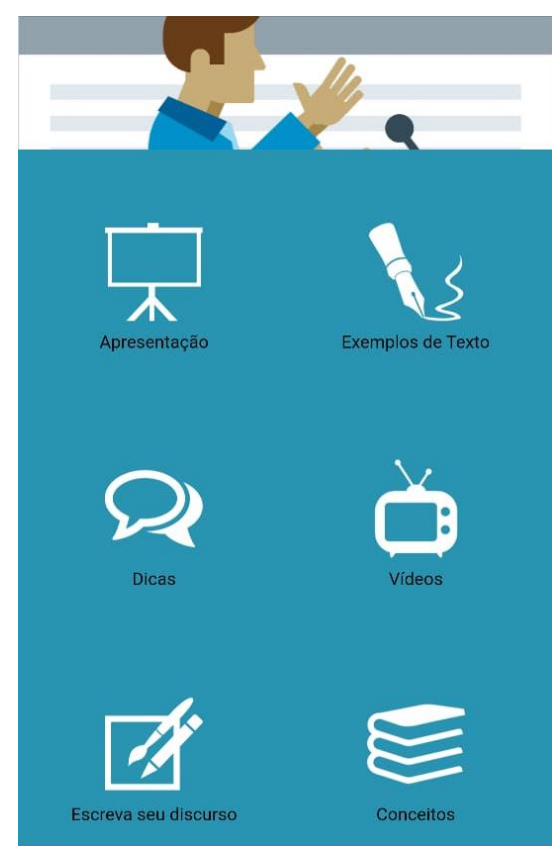

Fonte: Captura de tela (2018)

Merece destaque também o trabalho de edição de texto feito pelos acadêmicos, que transformaram o conteúdo em pequenas dicas de oratória e conceitos para leitura rápida no celular, o que ajuda a difundir o conteúdo em dispositivos móveis. Na parte de interação ficou aberto um espaço para a escrita de discursos que ficariam públicos e sujeitos a avaliação e opinião de outros usuários registrados.

Aplicativo Oratio - https://app.vc/oratio - No segundo trabalho selecionado, além de criar uma logomarca e buscar a identidade visual do APP acompanhando a própria logo, o grupo preferiu um formato de listagem dos recursos e o uso de ícones mais coloridos e de aspecto divertido. Entre os conteúdos estão apresentação, listagem de conceitos teóricos, artigos que tratam do tema, vídeos com discursos famosos, sugestões de filmes para quem gosta do tema oratória, dicas e um espaço com videoaulas, que seria 
um serviço a ser oferecido de forma comercial, uma possivel fonte de renda para os produtores do APP.

Figura 2. Aplicativo Oratio

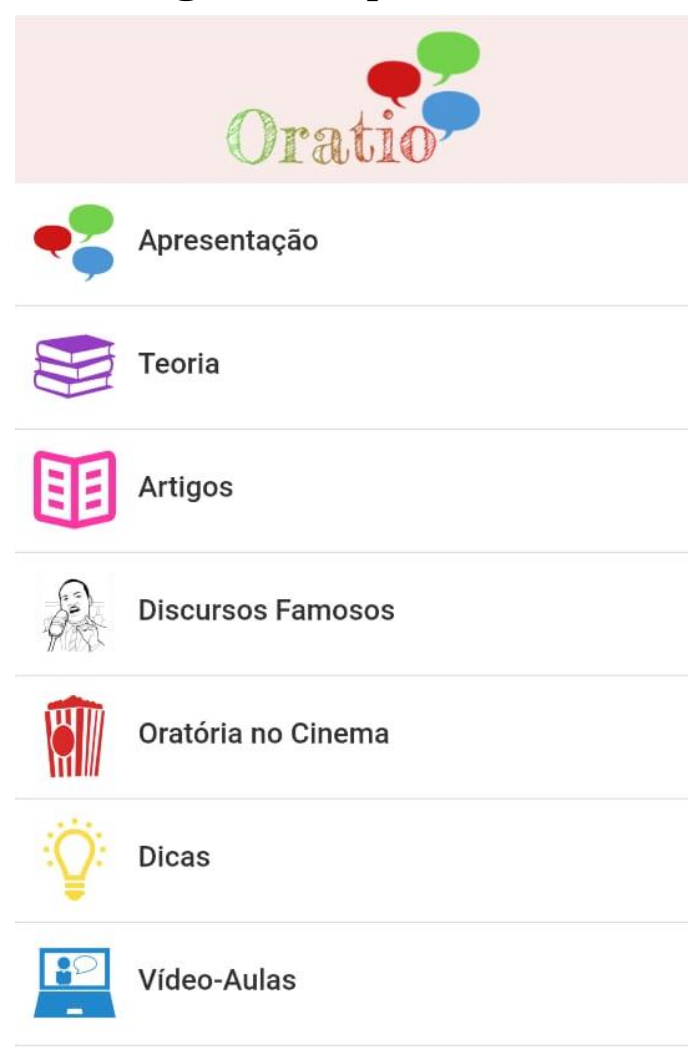

Fonte: Captura de tela (2018)

Não é possivel afirmar com certeza que a escolha de cores e de ícones foi boa ou ruim, isso vai depender do público e como ele será avaliado. Aplicativos que querem receber algum tipo de recurso, mesmo os feitos para crianças, tentam passar um efeito de sobriedade visual para aumentar a confiança dos possiveis consumidores. Em se tratando do conteúdo, o grupo foi pouco inventivo, preferindo ser um aplicativo que serve de atalho para a produção de outros autores na Internet, a partir da disponibilização de dicas e de artigos. A parte de teoria ficou pouco resumida, preferindo textos maiores para tratar dos conceitos de oratória.

Aplicativo Oratória - https://app.vc/oratoria - No terceiro trabalho os acadêmicos escolheram criar uma tela de abertura que depois se transformava no topo da tela do APP. Os ícones repetiam as mesmas cores, Interfaces da Educ., Paranaiba, v.11, n.32, p. 515 - 541, 2020 
estilizados com fundo transparente. Entre os recursos foram colocados um espaço com definições, conteúdos sobre oratória, vídeos de uma galeria do Youtube criada para o aplicativo, dicas, uma biblioteca virtual com sugestões de leitura e por fim um dicionário dos termos.

Figura 3. Aplicativo Oratória

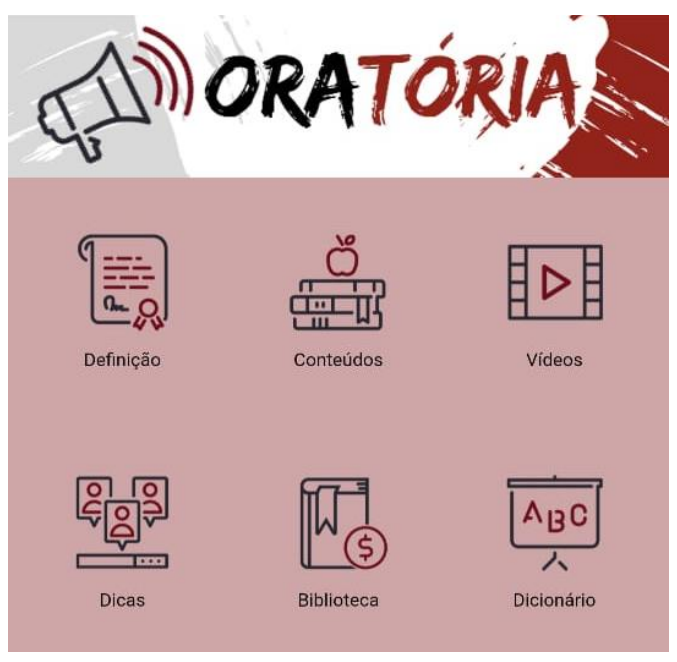

Fonte: Captura de tela (2018)

Um recurso muito bem utilizado foi o de biblioteca, no qual o leitor tem acesso ao livro completo na Internet; para isso os acadêmicos buscaram conteúdos gratuitos que pudessem ser disponibilizados. Na parte textual os acadêmicos optaram por textos grandes, não dividindo em pequenos tópicos, com um grande espaço para rolagem, deixando a experiência de consumo mais enfadonha e menos direta, já que para encontrar um determinado subtema será preciso rolar a página, em alguns casos bem avantajada de texto.

Aplicativo Fala Inteligente - https://app.vc/fala_inteligente - A proposta do nome do $A P P$, segundo os alunos explicaram durante a defesa dos projetos, era adotar um título que instigasse seus usuários a, ao falarem melhor, agregassem uma imagem de mais inteligência. A proposta desse APP foi de oferecer uma prestação de serviço, de ser menos acadêmico e mais voltado para o uso cotidiano, com dicas, vídeos entre outros. 
Figura 4. Aplicativo Fala Inteligente

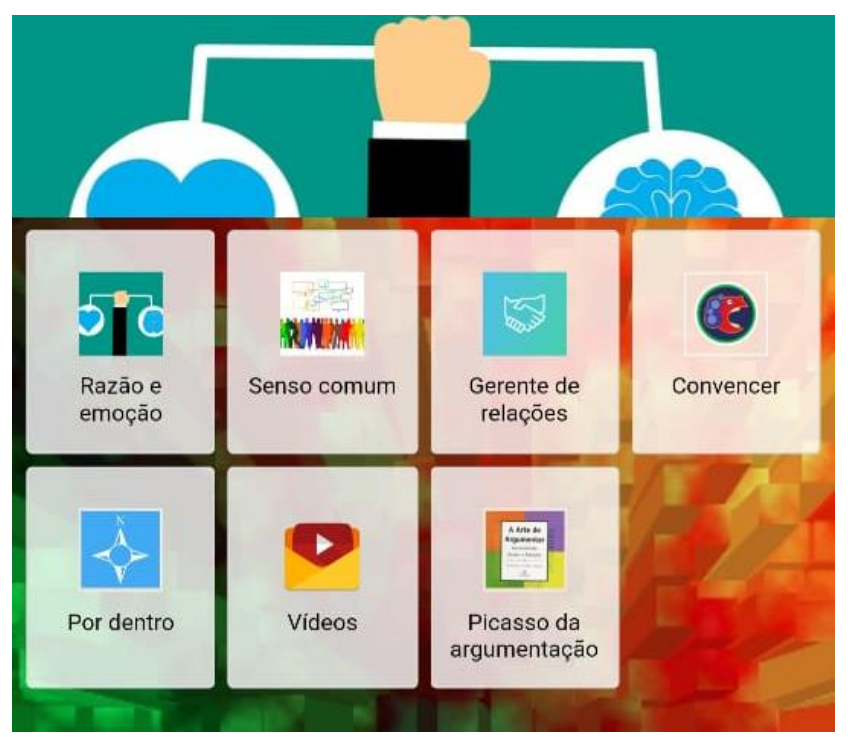

Fonte: Captura de tela (2018)

Faltou nesse exemplo mais profundidade de conteúdo. Os futuros jornalistas exageraram na busca pela redução dos textos, deixando pouco conteúdo para um aplicativo, colocando em xeque a necessidade de um aplicativo para tão pouco material. É louvável o exercício de leitura análise e resumo, mas neste caso fica também a reflexão de até que ponto isso deve ser levado. Um detalhe interessante foi o uso dos nomes de cada ícone, com uma abordagem mais direta sobre o tema, diferente dos outros que tratavam como dicas, conceitos. Este fala, inclusive, de razão e emoção, senso comum ou mesmo de "convencer" na argumentação, escolhas ousadas que ajudam a atrair leitura.

Aplicativo Argumente Now - https://app.vc/argumente_now - O quinto trabalho optou por uma imagem de fundo de um banco de imagens de distribuição gratuita na Internet que deu um aspecto visual agradável; os ícones seguem um padrão visual. Além de introdução ao tema, os estudantes colocaram vídeos, técnicas argumentativas, alertas contra falácias, exercícios, entre outros. 
Figura 5. Aplicativo Argumente Now

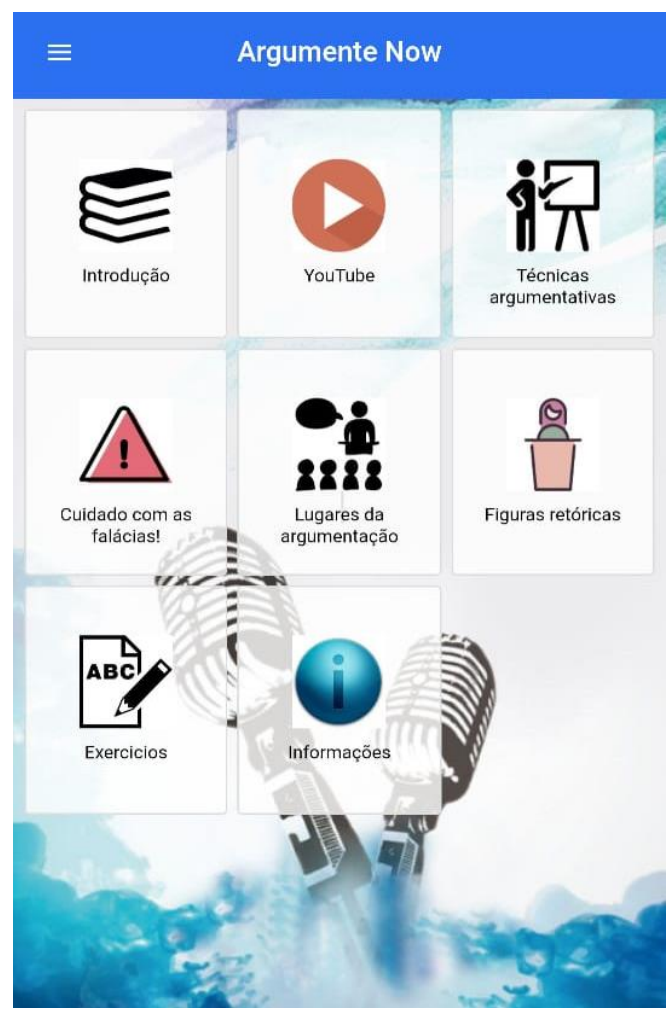

Fonte: Captura de tela (2018)

Este foi o aplicativo que mais compartimentalizou os conteúdos, separando-os em diversos tópicos e deixando uma enorme gama de informações separadas de forma muito bem organizada. Para isso os discentes, eles fizeram uma boa coleta e edição textual, atendendo uma das demandas do exercício proposto. Na parte de interação foi feita uma seleção de exercícios disponiveis online para os usuários acessarem, o que deu prosseguimento lógico no processo de aprendizado, unindo teoria e prática.

Outros aplicativos criados e que repetem basicamente o que já foi apresentado: Let's Talk - Oratória (https://app.vc/lets_talk__oratoria), Howto Speech (https://app.vc/how_to_speech), Argumentarte (https://app.vc/argumentarte),

Arte

de

Argumentar (https://app.vc/a_atrte_de_argumentare - o erro de digitação dos criadores ficou) e Oratória da Hora (https://m.app.vc/oratoria_da_hora). 
No geral os acadêmicos atenderam ao objetivo do exercício: traduzir conteúdos de um livro para uma forma adequada ao consumo em dispositivos móveis. Em alguns casos foi possível ver como o conhecimento da parte tecnológica permitiu que alguns alunos fizessem algumas ações mais desenvolvidas, como na parte visual com a construção de logos e ícones. A limitação e capacidade de cada um sempre vai ser parte do processo, mas também foi possivel ver que muitas das supostas limitações eram apenas imaginárias, já que muitos dos trabalhos foram além do que os próprios estudantes achavam ser possivel fazer. Incluir vídeos, exercícios, dicas entre outros, não foi uma tarefa inacessível, como eles próprios avaliam a seguir.

\section{Etapa 2: autoavaliação}

Uma vez vivenciada a experiência de criação dos aplicativos e de toda a atividade experimental, os discentes foram convidados a responder um questionário com cinco perguntas semiestruturadas com o intuito de entender como receberam esta metodologia de aprendizagem, suas dificuldades na execução das tarefas, seu processo criativo e se conseguiam enxergar o conhecimento adquirido como algo que pudesse ser aplicado na sua profissão no futuro. As respostas ajudaram a entender como eles vivenciaram essa experiência, onde encontraram mais dificuldades e até se acreditavam que poderiam comercializar o serviço de criação de aplicativos depois de formados.

A primeira questão tratou de saber do processo de criação - "Como foi o processo de criação do aplicativo? Faça um pequeno relato". A partir dela buscou-se levantar um panorama geral de como foi executar a tarefa para os estudantes. Foram $20^{5}$ alunos respondendo e de um modo geral eles admitiram que no início a atividade causou um certo receio, particularmente por parecer "complicado", mas rapidamente tornou-se simples, ampliou o conhecimento deles sobre o tema (oratória) e permitiu arriscar-se numa linguagem que não conheciam (produzir um $A P P$ ).

\footnotetext{
${ }^{5}$ Seis alunos não responderam o questionário.

Interfaces da Educ., Paranaíba, v.11, n.32, p. 515 - 541, 2020
} 
A princípio foi bem complicado, não sabia nem pra onde ia. Porém, quando fui conhecendo a plataforma, ficou mais fácil de fazer. A criação de conteúdo também foi bem legal, me senti designer criando a identidade visual e os ícones, é interessante pensar em cores que combinam, como elas conversam com a ideia do App (ALUNO 2, 2018 - entrevista).

Também vale citar que durante o processo eles reconheceram as restrições que a plataforma oferecia, mas que isso não foi um limitador preponderante no desenvolvimento do trabalho, inclusive os ajudou a entender as possibilidades que o software oferece e como trabalhar com isso. "Foi muito bacana, apesar de a plataforma ter algumas limitações, foi bem fácil de manusear e consegui botar na tela o que estava na minha cabeça" (ALUNO 12, 2018 - entrevista).

$\mathrm{Na}$ questão seguinte foi perguntado: "O que você levou em consideração enquanto criava seu $A P P$ ?”. A intenção era saber como, durante o processo criativo, os alunos estruturaram seu produto e, com isso, identificar possiveis obstáculos e atalhos. A maioria disse ter priorizado a entrega do conteúdo, como afirma o Aluno 13 (2018 - entrevista): "Queria apresentar o conteúdo de uma forma mais dinâmica, ainda com a forma de manual do livro, mas com exemplos mais simples, e também queria que o conteúdo ficasse bem dividido, separado".

O Aluno 4 (2018 - entrevista) reforça esse posicionamento: "O conteúdo, didática do conteúdo. Não queríamos apenas um App cheio de texto, então colocamos algumas facetas que se fosse para mim e a minha dupla baixar o APP, gostaria que tivesse. Pensamos no público!".

Tais respostas evidenciam uma preocupação dos estudantes em dialogar mais prontamente com seu público-alvo no sentido de ofertar um produto que não apenas contivesse informações, mas que fosse facilmente entendido, ou seja, uma ação pensada como profissional e não apenas como executor de uma tarefa da universidade. Isso demonstra interesse na atividade e também uma visão pragmática do aprendizado, o que é bastante positivo para uma formação que tenta mesclar o conhecimento humanístico e o mercado. Como a respostas era aberta, o fato de eles terem demonstrado 
essa preocupação de maneira espontânea é um resultado positivo porque mostra que essa preocupação com a audiência está naturalizada.

No entanto, alguns acadêmicos admitiram que tivessem como foco apenas as exigências das disciplinas, embora tenham sido a minoria. Estes, como ficou claro na fala do Aluno 5 (2018 - entrevista), fizeram a atividade preocupados, essencialmente, em atender "os requisitos de cada professor, das diferentes matérias", sem muita inquietação com o público, conteúdo ou linguagem.

A terceira questão foi sobre as dificuldades encontradas - "Quais foram suas principais dificuldades? Apesar de alguns citarem o uso da plataforma de criação, ela não foi tão comum e nem tão significativa. Pode-se perceber que tal ponderação teve mais a ver com o caráter de novidade, de ser uma informação desconhecida, que com a complexidade do recurso, como se vê na resposta do Aluno 4 (2018 - entrevista): "Foi entender as ferramentas que são do próprio App, mas depois conseguimos fazer. "Até mesmo porque o APP não é tão dificil de mexer".

A principal dificuldade acabou sendo mesmo o processo principal de adequação da linguagem. "Saber como colocar o conteúdo de oratória no App e não deixar ele chato. Tinha que fazer um App divertido de acessar, mas com os conteúdos de oratória" (ALUNO 5, 2018 - entrevista). Isso mostra que a dificuldade não é uma questão de tecnologia e demonstra que uma vez superado o receio inicial é tranquilamente possivel a um jornalista arriscar neste campo.

O tema linguagem, inclusive, foi tratado na pergunta seguinte - "O que mudou na linguagem do conteúdo quando foi para o APP?”. Assim, incentivou-se uma autoanálise do que eles fizeram e como transformaram o conteúdo. O Aluno 2 (2018 - entrevista) respondeu que "o conteúdo precisava ser mais chamativo, não dava pra colocar só texto. Precisava ser mais direto e objetivo também". Assim também explicou o Aluno 13 (2018 entrevista): "A forma com que o conteúdo se une ao entretenimento".

Outro discente destacou o uso dos recursos disponiveis nessa transformação: "A didática. Fizemos um quiz para melhor ficar as Interfaces da Educ., Paranaíba, v.11, n.32, p. 515 - 541, 2020 
informações, colocamos bastante imagens, vídeos e trava-línguas. O que não era possível ou não se via no livro" (ALUNO 4, 2018 - entrevista). Além disso, o APP ficou "mais direto", acredita o Aluno 8 (2018 - entrevista): "Ficou mais compacto e certeiro. Dessa forma, se você quer isso, é só clicar aqui”.

De um modo geral, nas explicações dos acadêmicos, fica claro o interesse pelo tema, pela novidade da linguagem dos aplicativos e como tais recursos, por fim, levam a atrair a atenção também para materiais mais tradicionais. Os estudantes mostraram que uma vez incentivados são capazes, por si mesmos, de promover uma integração de saberes.

As duas perguntas seguintes estavam interligadas - "Você acredita que esse tipo de criação você poderia vender como um serviço seu?" e "Quanto você acredita que custaria para fazer um aplicativo desses?". Ambas tinham como objetivo trazer o tema empreendedorismo, tão caro e necessário atualmente para os formados em Jornalismo, em um mercado que está inchado de profissionais nas áreas tradicionais, como redações e assessorias.

Apenas duas das 20 respostas foram negativas, ou seja, o aluno não acredita que esse conhecimento poderia ser transformado em uma atividade rentável ou vendável no sentido de produzir um serviço que gerasse lucro. Todos os demais acreditam que podem oferecer esse tipo de serviço, mesmo tento tido pouco tempo nesse trabalho, o que é muito positivo. Já no que tange definir um valor possível para cobrar pelo serviço, a maioria não soube quanto ele valeria. Os valores, dos que arriscaram dizer um, variaram de $R \$$ 50,00 a R\$ 2 mil, o que acaba sendo o retrato do mercado de Comunicação: a maioria não sabe o quanto cobrar pelos serviços, uns cobram muito, outros pouco. Isso levanta outro ponto a ser refletido sobre a formação do profissional: entender melhor o valor do seu serviço e conhecer o mercado e suas ofertas. 


\section{Etapa 3: avaliação externa}

Nesta última fase do experimento o aplicativo foi enviado pelos alunos para pessoas fora do âmbito da pesquisa que foram incentivadas a responder uma enquete para entender a receptividade do produto criado. Foram 203 respostas, mas é preciso reconhecer que o valor delas é limitado por vários fatores: não foi feita nenhuma limitação de público, então tem-se, provavelmente, amigos e conhecidos que responderam a pedido dos alunos, o que gera muito mais respostas positivas. No entanto, o objetivo não era só saber a opinião, mas também divulgar o trabalho.

A idade dos respondentes variou entre 14 e 54 anos, mas com uma concentração maior na casa dos 20 a 25 anos, o que reforça a questão da proximidade dos alunos, que têm em sua maioria essa faixa etária. $\mathrm{Na}$ questão da formação, a maioria está com ensino superior incompleto ou nível médio concluído, mais uma vez reforçando o que foi dito sobre a conexão com os estudantes.

Na parte de avaliação, foi colocado: De 0 a 10, sendo 0 a pior avaliação possível e 10 a melhor às seguintes características do aplicativo: Facilidade de Uso, Beleza do Aplicativo, Qualidade do Conteúdo, Variedade de Ferramentas e Clareza da exposição das informações.

Todas as respostas tiveram mais de $60 \%$ no nível máximo positivo, o que dificulta em muito a possibilidade de usar as respostas para fins científicos, mas esclarece na questão de que em uma próxima vez a pesquisa de avaliação não poderá ser incentivada pelos acadêmicos, mas que do ponto de vista de divulgação, os acadêmicos conseguiram um bom resultado, já que em menos de um dia foram mais de 200 respostas.

\section{Conclusão}

Este artigo relatou a experiência interdisciplinar realizada no curso de Jornalismo da Universidade Federal do Maranhão (campus Imperatriz), que resultou na criação de aplicativos para celular com conteúdo sobre Oratória e Argumentação. As disciplinas envolvidas foram Linguagem de Programação 
Visual e Oratória e o objetivo comum foi promover uma reflexão inicial sobre a formação na área e a viabilidade de incluir nesse processo estudos sobre linguagem de programação por meio da criação de aplicativos.

Os dados desta experiência, detalhada em formato de pesquisa aplicada, experimental e descritiva, advieram também de entrevistas com os alunos para autoavaliação, o que apontou questões relativas ao uso da tecnologia, linguagem e empreendedorismo; e pesquisa externa, com vistas a conhecer, especialmente, a viabilidade mercadológica dos produtos.

Os produtos, dados e análises apresentadas revelam que uma formação mais convergente e interdisciplinar é viável e necessária nos cursos de Jornalismo e que ela deve contemplar domínio técnico de algumas linguagens, como softwares, colaborando para o desenvolvimento de um jornalista mais preparado o mercado e mais autônomo para atuar na condução da sua própria carreira.

Esperamos contribuir para a criação de mais propostas interdisciplinares e convergentes nos cursos de Comunicação e Jornalismo, que atendam às exigências de formação de um jornalista digital multitarefa e, em um âmbito mais amplo, para a discussão sobre a formação mais adequada ao campo do Jornalismo.

\section{Referências}

ABREU, Antônio Suaréz. A arte de argumentar: Gerenciando razão e emoção. Cotia, SP: Ateliê Editorial, 2013.

ALBORNOZ, Luis. Periodismo digital:los grandes diarios en la Red. Buenos Aires: La Crujía, 2006.

BARBOSA, Suzana. Jornalismo convergente e continuum multimídia na quinta geração do jornalismo nas redes digitais. In: CANAVILHAS, João (Org). Notícias e mobilidade. [online]. Covilhã: Livros LabCom, 2013.

BECKER, Maria Lúcia. Convergente por formação: o novo paradigma e os desafios para as futuras gerações profissionais e os cursos de jornalismo. Revista Latino Americana da Jornalism. [online], v.3, n.1, p.100-124, 2016.

CALADO, Karolina de Almeida; JÚNIOR, José Afonso da Silva. Reflexos do mobile no Jornalismo. Esferas. [online], v.4, n. 6, p. 41-48, 2015. Interfaces da Educ., Paranaíba, v.11, n.32, p. 515 - 541, 2020 
CASTELLS, Manonel. A Galáxia da Internet: reflexões sobre a internet, os negócios e a sociedade. Rio de Janeiro: Jorge Zahar, 2003.

CASTELLS, Manoel et al. Mobile communication and society: a global perspective. Cambridge: MIT Press, 2007.

FÁBRICA DE APLICATIVOS. Sobre a Fábrica de Aplicativos. Fábrica de Aplicativos S/A. [online], 2019.

FRANCISCATO, Eduardo Carlos. A atualidade no jornalismo: Bases para sua delimitação teórica. 333f. Tese (Doutorado em Comunicação). Programa de Pós-Graduação em Comunicação e Culturas Contemporâneas, Faculdade de Comunicação, Universidade Federal da Bahia, Bahia, 2003.

- Uma proposta de incorporação dos estudos

sobre inovação nas pesquisas em jornalismo. Estudos em Jornalismo e Mídia. [online], v. 7 n. 1, p. 8-18, 2010.

JAPIASSU, Hilton. Interdisciplinaridade e patología do saber. Rio de Janeiro: Imago, 1976.

LEMOS, André. Cibercultura e Mobilidade: a Era da Conexão. Revista Razón y Palabra. [online], v1, n41, s/p, 2004.

SILVA, Rafael Pereira; LOPES, Boanerges Balbino. Mudanças estruturais e ensino de Jornalismo: o papel do professor nos novos rumos do jornalismo brasileiro. Intext. [online], n. 35, p. 137-153, 2016.

MACHADO, Elias; PALACIOS, Marcos. Um modelo híbrido de pesquisa: a metodologia aplicada pelo GJOL. In: LAGO, Cláudia; BENETTI, Marcia (Orgs.). Metodologia de Pesquisa em Jornalismo. Petrópolis: Vozes, 2010.

MARCONDES FILHO, Ciro. A saga dos cães perdidos. São Paulo, HackerEditores, 2000.

MARCONI, Maria; LAKATOS, EVA Maria. Metodologia do Trabalho Científico. São Paulo: Atlas, 1992.

MARSHAL, Leandro. O novo perfil do jornalista brasileiro: indiferença política é marcante. Desacato. [online], 14/05/2013.

MORETZSOHN, Silvia. Jornalismo em tempo real: o fetiche da velocidade. Rio de Janeiro: Revan, 2002. 
SAAD, Elizabeth Corrêa. Estratégias para a midia digital: Internet, informação e comunicação. São Paulo: Senac, 2003.

. Centralidade, transversalidade e resiliência: reflexões sobre as três condições da contemporaneidade digital e a epistemologia da Comunicação. In: CONGRESSO INTERNACIONAL IBERCOM. São Paulo. Anais. São Paulo, 2015.

SANTAELlA, Lucia. Comunicação e Pesquisa-Projetos para Mestrado e Doutorado. São Paulo: Hacker Editores, 2001.

SANTOS, Raissa Nascimento dos. Jornalismo do Século XXI: profissão, identidade, papel social, desafios contemporâneos. In: XVI CONGRESSO DE CIÊNCIA DA COMUNICAÇÃO NA REGIÃO NORDESTE. Anais. Paraíba, 2014.

SCOLARI, Carlos Alberto. A comunicação móvel está no centro dos processos de convergência cultural contemporâneos. Entrevista concedida a Alan César Belo Angeluci. Intercom. [online], v.39, n.2, p.177-184, 2016.

SCHWINGEL, Caru. Entrevista Caru Schwingel defende incluir programação digital na formação do novo jornalista. Observatório, [online], v1, n.2, p.285264, 2015. 